\title{
PENGEMBANGAN SISTEM JARINGAN AIR BERSIH DENGAN METODE GRAVITASI DI DESA BATU TERING KECAMATAN MOYO HULU
}

\author{
ADY PURNAMA ${ }^{1}$, BADARUDDIN ${ }^{2}$, ABDUL HARIS ${ }^{3}$ \\ ${ }^{1,2}$ Dosen Program Studi Teknik Sipil Fakultas Teknik Universitas Samawa Sumbawa Besar \\ ${ }^{3}$ Mahasiswa Program Studi Teknik Sipil Fakultas Teknik Universitas Samawa Sumbawa Besar
}

\begin{abstract}
Abstrak
Desa Batu tering merupakan salah satu desa yang terletak di Kecamatan Moyo Hulu, yang terbagi kedalam empat dusun, yaitu dusun Batu Tering A, dusun Batu tering B, dusun Sela dan dusun Melung. Di desa Batu tering sebelumnya sudah terdapat sistem air bersih tapi belum mampu memenuhi kebutuhan air bersih desa secara maksimal. Perencanaan sistem air bersih dilakukan dengan cara menangkap air dari mata air dengan menggunakan bangunan penangkap mata air (broncaptering) kemudian disalurkan dengan sistem gravitasi (gravity system) ke reservoir distribusi, selanjutnya air didistribusikan ke penduduk melalui sambungan rumah (SR) dengan sistem gravitasi.

Kebutuhan air bersih desa Batu Tering sebesar 3.07 I/detik dihitung berdasarkan proyeksi jumlah penduduk yang pertumbuhannya dianalisis dengan menggunakan Metode geometrik, untuk tahun 2035 dengan jumlah penduduk sebanyak 2370 jiwa.Ukuran bak penangkap mata air $(2 \times 1,5 x$ $1,5) m$ dan ukuran reservoir distribusi $(5 \times 4 \times 2.7) m$. Dalam perencanaan sistem air bersih di desa Batu Tering digunakan jenis pipa PVC diameter 3" untuk pipa transmisi, dan pipa 1 1/4 "dan 3/4" sebagai pipa distribusi SR.
\end{abstract}

Kata kunci : Desa Batu Tering, Sistem Air Bersih, SR, Pengembangan Sistem, Metode Gravitasi.

\section{PENDAHULUAN}

Seiring dengan pertambahan jumlah penduduk dan pengembangan penataan kota mengakibatkan bertambahnya juga kebutuhan air. Dari keseluruhan jumlah air di muka bumi terdapat $97 \%$ berada di lautan,dan hanya $3 \%$ yang merupakan air bersih, dari $3 \%$ ini $30 \%$ nya air tanah, $68.7 \%$ nya dalam bentuk es dan gletser dan hanya $1.2 \%$ yang merupakan air permukaan yang berada di sungai, danau, dan sebagainya. Air di bumi ini mengulangi terus menerus sirkulasi yaitu penguapan, presipitasi dan pengaliran keluar (outflow). Sehingga dapat disimpulkan bahwa sumber daya air di muka bumi ini tidak akan bertambah jumlahnya. Di lain pihak, air menjadi kebutuhan penting bagi kehidupan makhluk hidup, khususnya kebutuhan akan air bersih. Sejalan dengan pertambahan dan perkembangan penduduk, maka kebutuhan terhadap air bersih juga semakin meningkat, persaingan untuk mendapatkan air bersih untuk berbagai macam kepentingan pun juga akan terus meningkat. Perkembangan wilayah pada suatu daerah akan menyebabkan kebutuhan air bersih terus meningkat seiring dengan laju pertumbuhan penduduk. Pemenuhan kebutuhan pangan dan aktivitas penduduk selalu erat kaitannya dengan kebutuhan akan air bersih. Tuntutan tersebut tidak dapat dihindari, tetapi haruslah diprediksi dan direncanakan pemanfaatan sebaik mungkin.

Indonesia sendiri mempunyai potensi sumber daya air yang berlimpah dengan total sekitar 3900 miliar $\mathrm{m}^{3}$ per tahun yang tersebar di 7956 sungai dan 521 danau. Persedian air di indonesia hingga $6 \%$ dari persediaan air dunia. Tapi dari tahun ke tahun indonesia mengalami krisis air bersih . data BAPPENAS 2011 menunjukkan $85 \%$ rakyat indonesia menggunakan air yang tidak layak bagi kesehatan.

Provinsi Nusa Tenggara Barat merupan salah satu provinsi yang jumlah pertumbuhan penduduknya cukup besar dan kebutuhan air bersihnya jugan cukup tinggi. Kabupaten Sumbawa merupakan kabupaten yang kepadatan penduduknya tidak terlalu padat dan memiliki sumber daya air bersih yang cukup banyak. 
Kecamatan Moyo Hulu merupakan kecamatan yang terletak di bagian selatan pulau Sumbawa dan memimiliki 9 desa. Kepadatan penduduknya juga masi bisa dibilang kurang padat dan sistem air bersihnya juga masi sangat minim, sekalipun ada sistem air bersih tersebut tidak beroperasi dengan baik, sebagian besar masyarakan masi mengandalkan sumur sebagai sumber air bersih. Hal tersebut belum mampu menyediakan air bersih hingga akhir musim kemarau. Desa Batu Tering terletak di Kecamatan Moyo Hulu, yang terbagi kedalam empat dusun, yaitu dusun Batu Tering A, dusun Batu Tering $B$, dusun Sela dan dusun Melung. Di desa Batu Tering sudah terdapat sistem air bersih tapi belum mampu memenuhi kebutuhan aiar bersih desa secara maksimal. Dan beberapa masalah juga sering terjadi seperti kurang mampunya memenuhi kebutuhan air di musim kemarau, sering terjadinya kerusakan pipa jika debit air sungai meningkat saat terjadinya hujan, kurang bersihnya air pada musim penghujan, serta daerah cakupannya belum maksimal, masi ada satu dusun yang tidak mendapat suplai air bersih.

Berdasarkan permasalahan diatas sehingga sangat diperlukan perhatian untuk mencari solusi dari berbagai masalah yang dimaksud, maka dari keadaan tersebut saya akan melakukan penelitian, dengan tema "Pengembangan Sistem Jaringan Air Bersih dengan Metode Gravitasi di Desa Batu Tering Kecamatan Moyo Hulu Kabupaten Sumbawa".

\section{METODE PENELITIAN}

Penelitian ini berasal dari minat untuk mengetahui masalah tertentu dan selanjutnya berkembang menjadi pemilihan metode yang sesuai. Ide ini meliputi latar belakang permasalahan yang terjadi di Desa Batu Tering Kecamatan Moyo Hulu Kabupaten Sumbawa berkaitan dengan kebutuhan dan sistem air bersih. Dan diharapkan dengan penelitian ini mahasiswa dapat berpikir ilmiah, mampu menuangkan sebagian besar pengetahuan, ketrampilan, ide dan masalah dalam bidang keahlian secara sistematis, logis, kritis dan kreatif yang didukung oleh data atau informasi dengan analisa yang tepat. Gambar lokasi penelitian dibawah ini :

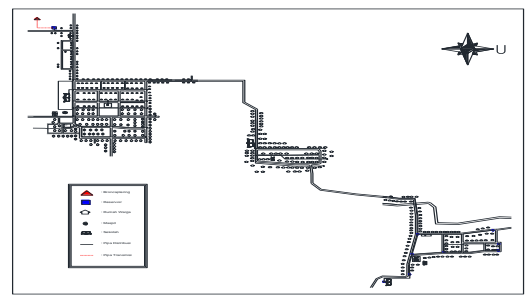

Gambar 1. Desa Batu Tering (Google Eart,2016)

\section{Lokasi Penelitian}

Penelitian tugas akhir ini berlokasi di Kecamatan Moyo Hulu dimana wilayah yang di tinjjau adalah Desa Batu Tering.

\section{Pengumpulan Data}

Data yang dibutuhkan dalam penelitian adalah data primer dan data sekunder.

a. Data Primer

Data primer yang didapatkan merupakan data yang didapatkan dari Instasi terkait dan selain itu data dari informasi masyarakat dan pengamatan langsung mengenai kondisi lapangan di Kecamatan Moyo Hulu, Kabupaten Sumbawa. Berupa jarak mata air ke desa, debit mata air. Peta siteplan.

b. Data Sekunder

Data sekunder merupakan data pendukung yang dipergunakan dalam menganalisis permasalahan juga teori-teori yang dijadikan referensi kaitan dengan persoalan pada desa setempat. Peta diperoleh dari BAPPEDA Kabupaten Sumbawa berupa peta Administrasi Wilayah Kabupaten Sumbawa, peta kontur, dan peta kemiringan lahan kabupaten sumbawa, serta data jumlah penduduk.

\section{Tahapan Penelitian}

Tahapan-tahapan penelitian disajikan pada gambar 3.1, secara rinci dapat diuraikan sebagai berikut :

\section{Studi Pustaka}

Tahap studi pustaka yaitu mengumpulkan dan mempelajari bahan-bahan yang berhubungan dengan masalah-masalah yang diteliti. Bahan-bahan tersebut berupa bahan yang didapat dari tulisan-tulisan ilmiah, diktatdiktat, buku-buku maupun internet yang berkaitan dengan masalah yang diteliti. Dalam hal ini data yang diperoleh berupa literature 
mengenai hal-hal yang berkaitan dengan masalah yang akan dibahas.

\section{Pengumpulan Data}

Tahap ini merupakan tahap pengumpulan data-data yang berhubungan dengan analisa kebutuhan air dan perencanaan instalasi pengolahan air. Beberapa data yang dikumpulkan yaitu :

a. Data jumlah penduduk tiap-tiap dusun di desa Batu Tering, Kecamatan Moyo Hulu.

b. Data fasilitas-fasilitas umum yang tersedia di Desa Batu Tering.

c. Peta-peta administrasi dan data penunjang lainnya.

\section{Pengolahan Data}

Dalam tahap ini yang dilakukan adalah mengolah data yang sudah didapat untuk dijadikan data awal dalam melakukan analisa dan perhitungan. Perhitungan yang dilakukan berkaitan dengan perencanaan jaringan perpipaan dan analisa kebutuhan air bersih yaitu kebutuhan air domestik dan kebutuhan air non domestik pada kondisi sekarang dan yang akan datang di Desa Batu Tering.

\section{HASIL DAN PEMBAHASAN}

\section{Analisa Pertumbuhan Penduduk}

Jumlah penduduk mempengaruhi tingkat kebutuhan air bersih. Peningkatan jumlah penduduk dari masa ke masa memberikan pengaruh signifikan terhadap tingkat kebutuhan air bersih. Untuk mengetahui kebutuhan air bersih di masa yang akan datang, maka diperlukan data jumlah penduduk di masa datang. Jumlah penduduk di masa datang diperoleh dengan melakukan proyeksi penduduk.

Perhitungan proyeksi pertumbuhan penduduk menggunakan metode aritmatika dan metode geometrik, seperti diperlihatkan pada rumus 2.4 dan 2.6. Untuk Desa Batu Tering, penduduk diproyeksikan per dusun dimana desa Batu tering terdiri dari Dusun Batu Tering A, Dusun Batu tering B, Dusun Sela, dan Dusun Melung. Berikut adalah perhitungan proyeksi penduduk untuk masing - masing Dusun.
2. Perhitungan Proyeksi Penduduk Desa Batu Tering.

Perhitungan Proyeksi Jumlah Penduduk desa Batu Tering akan dihitung dengan rumus 2.6.

a. Persentase pertambahan penduduk ratarata tiap tahun

$$
\begin{aligned}
r & =16.89 \% / 9 \\
& =1.89 \%
\end{aligned}
$$

\begin{tabular}{|c|c|c|c|c|c|c|}
\hline \multirow[b]{2}{*}{ No } & \multirow[b]{2}{*}{ Tahun } & \multicolumn{4}{|c|}{ Dusun } & \multirow[b]{2}{*}{ Jumlah } \\
\hline & & $\begin{array}{c}\text { Batu } \\
\text { Tering } \\
\text { A }\end{array}$ & $\begin{array}{c}\text { Batu } \\
\text { Tering } \\
\text { B }\end{array}$ & Sela & Melung & \\
\hline 1 & 2006 & 384 & 396 & 292 & 302 & 1374 \\
\hline 2 & 2007 & 389 & 402 & 297 & 307 & 1395 \\
\hline 3 & 2008 & 396 & 409 & 303 & 314 & 1422 \\
\hline 4 & 2009 & 403 & 416 & 309 & 319 & 1447 \\
\hline 5 & 2010 & 411 & 425 & 316 & 325 & 1477 \\
\hline 6 & 2011 & 417 & 433 & 321 & 331 & 1502 \\
\hline 7 & 2012 & 424 & 441 & 329 & 339 & 1533 \\
\hline 8 & 2013 & 432 & 450 & 336 & 346 & 1564 \\
\hline 9 & 2014 & 441 & 458 & 345 & 353 & 1597 \\
\hline 10 & 2015 & 449 & 467 & 354 & 361 & 1631 \\
\hline
\end{tabular}

Tabel 1. Jumlah Penduduk desa Batu Tering

b. Proyeksi Penduduk dengan Metode

Geometrik

Perhitungan Proyeksi Penduduk batu Tering A untuk 20 tahun yang akan datang.

$$
\begin{aligned}
& \mathrm{Pn}=P(1+n)^{n} \\
& \mathrm{P} 20=1631(1+0.0189)^{20} \\
& \text { P20 = } 2370 \text { Jiwa }
\end{aligned}
$$

Jadi jumlah penduduk di desa Batu tering dari tahun 2106-2035 dapat dilihat pada Tabel 2 :

Tabel 2. Pertumbuhan penduduk desa Batu Tering Tahun 2016-2035

\begin{tabular}{|c|c|c|c|c|c|c|}
\hline \multirow{N}{N}{} & \multirow{2}{*}{$\begin{array}{c}\text { Tahu } \\
\text { n }\end{array}$} & $\begin{array}{c}\text { Batu } \\
\text { Terin } \\
\text { g A }\end{array}$ & $\begin{array}{c}\text { Batu } \\
\text { Tering } \\
\text { B }\end{array}$ & Sela & $\begin{array}{c}\text { Melu } \\
\text { ng }\end{array}$ & $\begin{array}{c}\text { Pumlah } \\
\text { duk }\end{array}$ \\
\hline 1 & 2016 & 457 & 476 & 361 & 368 & 1662 \\
\hline 2 & 2017 & 466 & 485 & 367 & 375 & 1693 \\
\hline 3 & 2018 & 475 & 494 & 374 & 382 & 1725 \\
\hline 4 & 2019 & 484 & 503 & 381 & 389 & 1758 \\
\hline 5 & 2020 & 493 & 513 & 389 & 396 & 1791 \\
\hline 6 & 2021 & 502 & 522 & 396 & 404 & 1825 \\
\hline 7 & 2022 & 512 & 532 & 403 & 411 & 1859 \\
\hline 8 & 2023 & 521 & 542 & 411 & 419 & 1894 \\
\hline 9 & 2024 & 531 & 553 & 419 & 427 & 1930 \\
\hline 10 & 2025 & 541 & 563 & 427 & 435 & 1966 \\
\hline 11 & 2026 & 552 & 574 & 435 & 443 & 2003 \\
\hline 12 & 2027 & 562 & 584 & 443 & 452 & 2041 \\
\hline 13 & 2028 & 573 & 595 & 451 & 460 & 2080 \\
\hline 14 & 2029 & 583 & 607 & 460 & 469 & 2119 \\
\hline 15 & 2030 & 594 & 618 & 469 & 478 & 2159 \\
\hline 16 & 2031 & 606 & 630 & 477 & 487 & 2200 \\
\hline 17 & 2032 & 617 & 642 & 486 & 496 & 2241 \\
\hline 18 & 2033 & 629 & 654 & 496 & 505 & 2283 \\
\hline 19 & 2034 & 640 & 666 & 505 & 515 & 2327 \\
\hline 20 & 2035 & 653 & 679 & 514 & 525 & 2370 \\
\hline
\end{tabular}




\section{Proyeksi Pertumbuhan Siswa}

Tabel 3. Jumlah Siswa di Desa Batu Tering

\begin{tabular}{|c|c|c|c|c|}
\hline \multirow{2}{*}{ NO } & \multirow{2}{*}{ TAHUN } & \multirow{2}{*}{ Jumlah } & \multicolumn{2}{|c|}{$\begin{array}{c}\text { Pertumbuhan } \\
\text { Penduduk }\end{array}$} \\
\cline { 4 - 5 } & & & Jiwa & Persentase \\
\hline 1 & 2006 & 519 & - & \\
\hline 2 & 2007 & 525 & 6 & $1.1 \%$ \\
\hline 3 & 2008 & 528 & 3 & $0.6 \%$ \\
\hline 4 & 2009 & 537 & 9 & $1.7 \%$ \\
\hline 5 & 2010 & 540 & 3 & $0.6 \%$ \\
\hline 6 & 2011 & 541 & 1 & $0.2 \%$ \\
\hline 7 & 2012 & 546 & 5 & $0.9 \%$ \\
\hline 8 & 2013 & 552 & 6 & $1.1 \%$ \\
\hline 9 & 2014 & 557 & 5 & $0.9 \%$ \\
\hline 10 & 2015 & 563 & 6 & $1.1 \%$ \\
\hline \multicolumn{3}{|c|}{ Jumlah } & \multicolumn{3}{c}{$8.1 \%$} \\
\hline
\end{tabular}

Perhitungan Proyeksi Jumlah Siswa akan dihitung dengan rumus 2.6 :

a. Persentase pertambahan Siswa rata-rata tiap tahun

$$
\begin{aligned}
& r=8.09 \% / 9 \\
& r=0.90 \%
\end{aligned}
$$

b. Proyeksi Pertumbuhan Penduduk Perhitungan Proyeksi Siswa Desa Batu Tering untuk 20 tahun yang akan datang

$$
\begin{aligned}
& \text { Pn }=\mathrm{P}(1+\mathrm{n})^{\mathrm{n}} \\
& \text { P20 }=563(1+0.0090)^{20} \\
& \text { P20 }=673 \text { Siswa }
\end{aligned}
$$

Jadi jumlah siswa di desa Batu Tering dari tahun 2106-2035 dapat dilihat pada Tabel 4.

Tabel 4 : Jumlah siswa tahun 2016 - 2035

\begin{tabular}{|c|c|c|c|c|c|c|c|}
\hline No & Tahun & TK & TK & SDN & SDN & SMP & Sisw \\
\hline 1 & 2016 & 25 & 23 & 177 & 157 & 186 & 568 \\
\hline 2 & 2017 & 25 & 23 & 178 & 159 & 187 & 573 \\
\hline 3 & 2018 & 26 & 24 & 180 & 160 & 189 & 578 \\
\hline 4 & 2019 & 26 & 24 & 181 & 162 & 191 & 584 \\
\hline 5 & 2020 & 26 & 24 & 183 & 163 & 192 & 589 \\
\hline 6 & 2021 & 26 & 24 & 185 & 165 & 194 & 594 \\
\hline 7 & 2022 & 27 & 24 & 186 & 166 & 196 & 599 \\
\hline 8 & 2023 & 27 & 25 & 188 & 168 & 198 & 605 \\
\hline 9 & 2024 & 27 & 25 & 190 & 169 & 199 & 610 \\
\hline 10 & 2025 & 27 & 25 & 191 & 171 & 201 & 616 \\
\hline 11 & 2026 & 28 & 25 & 193 & 172 & 203 & 621 \\
\hline 12 & 2027 & 28 & 26 & 195 & 174 & 205 & 627 \\
\hline 13 & 2028 & 28 & 26 & 197 & 175 & 207 & 632 \\
\hline 14 & 2029 & 28 & 26 & 198 & 177 & 209 & 638 \\
\hline 15 & 2030 & 29 & 26 & 200 & 178 & 210 & 644 \\
\hline 16 & 2031 & 29 & 27 & 202 & 180 & 212 & 650 \\
\hline 17 & 2032 & 29 & 27 & 204 & 182 & 214 & 656 \\
\hline 18 & 2033 & 29 & 27 & 206 & 183 & 216 & 661 \\
\hline 19 & 2034 & 30 & 27 & 207 & 185 & 218 & 667 \\
\hline 20 & 2035 & 30 & 28 & 209 & 187 & 220 & 673 \\
\hline
\end{tabular}

\section{Analisa Debit Air}

Berdasarkan hasil penelitian di peroleh debit air yang mampu di hasilkan oleh mata air di desa Batu Tering dapat dilihat pada tabel 5.

Tabel 5. Pengukuran debit mata air

\begin{tabular}{|c|c|c|c|c|c|c|}
\hline \multirow{2}{*}{ No } & \multirow{2}{*}{ Uraian } & \multicolumn{5}{|c|}{ Pengukuran Ke } \\
\cline { 3 - 6 } & & 1 & 2 & 3 & 4 & 5 \\
\hline 1 & Debit (I/dtk) & 5.2 & 5.3 & 5.1 & 5.2 & 5.1 \\
\hline 2 & Rata-rata & \multicolumn{5}{|c|}{5.18 (I/dtk) } \\
\hline
\end{tabular}

5. Analisa Kebutuhan Air Bersih Pada Tahun Rencana

Dibawah ini adalah perhitungan proyeksi kebutuhan air bersih di Desa Batu Tering tahun 2035. Besar kebutuhan air bersih di desa Batu Tering untuk kebutuhan domestic dan non domestik adalah:

\section{Kebutuhan domestik}

Berdasarkan Tabel 2.1 di peroleh konsumsi air rata-rata SR adalah $90 \mathrm{Itr} / \mathrm{org} /$ hari. Berikut perhitungan kebutuhan air domestik desa Batu Tering :

a. Kebutuhan Sambungan Rumah (SR)

Kebutuhan SR pada tahun 2035 dapat dihitung dengan cara :

$$
\begin{aligned}
& \mathrm{P} 2035=2370 \\
& \begin{aligned}
\mathrm{Q} 35 & =\mathrm{Pn} \times 90 \mathrm{l} / \mathrm{hr} \\
& =2370 \times 90 \\
& =213300 \mathrm{l} / \mathrm{hr}=2.47 \mathrm{l} / \mathrm{dtk}
\end{aligned}
\end{aligned}
$$

\begin{tabular}{|c|c|c|c|c|c|}
\hline \multirow{2}{*}{ No } & \multirow{2}{*}{ Tahun } & \multirow{2}{*}{$\begin{array}{l}\text { Jumlah } \\
\text { Pendu } \\
\text { duk }\end{array}$} & \multirow{2}{*}{$\begin{array}{c}\text { jenis } \\
\text { Sambun } \\
\text { gan } \\
\text { Dometik } \\
\text { SR ( } 90 \\
\text { I/Org/hr) }\end{array}$} & \multicolumn{2}{|c|}{$\begin{array}{c}\text { Jumlah } \\
\text { Kebutuhan Air }\end{array}$} \\
\hline & & & & $(\mathrm{l} / \mathrm{hr})$ & $\begin{array}{c}(1 / \mathrm{dt} \\
\mathrm{k})\end{array}$ \\
\hline 1 & 2016 & 1662 & 149560 & 149560 & 1.73 \\
\hline 2 & 2017 & 1693 & 152382 & 152382 & 1.76 \\
\hline 3 & 2018 & 1725 & 155257 & 155257 & 1.80 \\
\hline 4 & 2019 & 1758 & 158187 & 158187 & 1.83 \\
\hline 5 & 2020 & 1791 & 161172 & 161172 & 1.8 \\
\hline 6 & 2021 & 1825 & 164213 & 164213 & 1.90 \\
\hline 7 & 2022 & 1859 & 167312 & 167312 & 1.94 \\
\hline 8 & 2023 & 1894 & 170469 & 170469 & 1.97 \\
\hline 9 & 2024 & 1930 & 173686 & 173686 & 2.01 \\
\hline 10 & 2025 & 1966 & 176963 & 176963 & $2.0 \stackrel{3}{3}$ \\
\hline 11 & 2026 & 2003 & 180302 & 180302 & 2.05 \\
\hline 12 & 2027 & 2041 & 183705 & 183705 & 2.13 \\
\hline 13 & 2028 & 2080 & 187171 & 187171 & $2.1 \dot{1}$ \\
\hline 14 & 2029 & 2119 & 190703 & 190703 & 2.21 \\
\hline 15 & 2030 & 2159 & 194301 & 194301 & 2.25 \\
\hline 16 & 2031 & 2200 & 197968 & 197968 & $2.2 \mathrm{~s}$ \\
\hline 17 & 2032 & 2241 & 201703 & 201703 & 2.33 \\
\hline 18 & 2033 & 2283 & 205509 & 205509 & 2.38 \\
\hline 19 & 2034 & 2327 & 209387 & 209387 & 2.42 \\
\hline 20 & 2035 & 2370 & 213338 & 213338 & $2.4 \pi$ \\
\hline
\end{tabular}

Untuk perhitungan lengkapnya kebutuhan air domestik desa Batu Tering tahun 20162035dapat di lihat pada Tabel 6 .

Tabel 6. Perhitungan Kebutuhan Air Domestik desa Batu Tering 


\section{Kebutuhan Air non Domestik}

Untuk fasilitas domestik dapat di asumsikan bahwa jumlah fasiltas desa yang ada masih bisa digunakan hingga 20 tahun ke depan.

Tabel 7. Jumlah fasilitas desa Batu Tering.

\begin{tabular}{|c|c|c|c|c|c|c|c|}
\hline No & Dusun & Puskesmas & masjid & posyandu & TK & $S D$ & SIMP \\
\hline 1 & $\begin{array}{l}\text { Batu } \\
\text { Tering } \\
\text { A }\end{array}$ & 1 & \multirow{2}{*}{1} & 1 & - & - & \\
\hline 2 & $\begin{array}{c}\text { Batu } \\
\text { Teering } \\
\text { B } \\
\end{array}$ & - & & - & 1 & 1 & \\
\hline 3 & Sela & - & 1 & 1 & - & 1 & 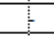 \\
\hline 4 & Melung & - & 1 & 1 & 1 & - & \\
\hline
\end{tabular}

Berdasarkan Tabel.7 Kebutuhan Air Besih non Domestik Desa batu Tering dapat di hitung.

Fasilitas Pendidikan Q di butuhkan :

= Jumlah Siswwa $\times$ Standar kebutuhan air

$=673 \times 5 \mathrm{l} / \mathrm{siswa}$

$=3367 \mathrm{I} / \mathrm{siswa} /$ hari

$=0.039 \mathrm{I} / \mathrm{siswa} / \mathrm{dtk}$

Data lengkapnya dapat dilihat pada tabel 8 .

Tabel 8 : Kebutuhan air non domestic

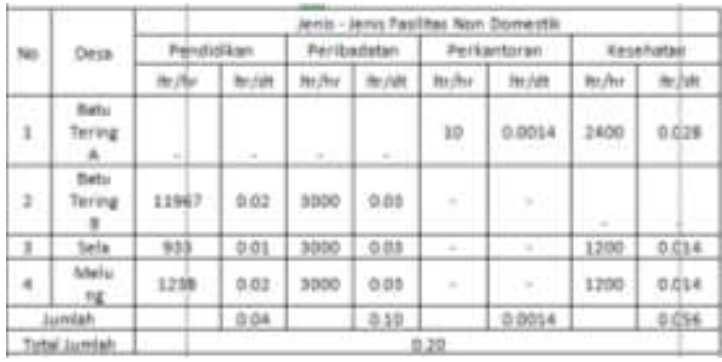

\section{Analisis Kehilangan air}

Kehilangan air pada umumnya disebabkan karena adanya kebocoran air pada pipa transmisi dan distribusi serta kesalahan dalam pembacaan meter. Berdasarkan tabel 7 kebocora /kehilangan air yaitu sebesar 15\% dari kebutuhan rata-rata dimana kebutuhan rata-rata adalah jumlah dari kebutuhan domestik ditambah dengan kebutuhan non domestic.

$$
\begin{aligned}
\text { Kehilangan air } & =\text { Qr } \times 15 \% \\
& =2.67 \times 15 \% \\
& =0.40 \mathrm{l} / \mathrm{dtk}
\end{aligned}
$$

\section{Analisis Kebutuhan Air Total}

Kebutuhan air total adalah total kebutuhan air baik domestik, non domestik ditambah kehilangan air.

$$
\begin{aligned}
Q t & =\underset{\quad \text { non domestic }+Q \text { domestic }+Q}{\text { kehilangan }} \\
& =0.20+2.47+0.40 \\
& =3.07 \mathrm{l} / \mathrm{dtk}
\end{aligned}
$$

\section{Kebutuhan Air Maksimum dan Jam Puncak}

Kebutuhan air harian maksimum dihitung berdasarkan faktor pengali yaitu 1,15-1,25 di kali dengan kebutuhan air total. Kebutuhan air jam puncak dihitung berdasarkan faktor pengali yaitu 1,65-1,75 dikali dengan kebutuhan air total

$$
\begin{aligned}
& \text { a. Kebutuhan Air Maksimum } \\
& Q_{\max }=\text { Qt } \times 1.25 \\
& =3.07 \times 1.25 \\
& =3.84 \mathrm{l} / \mathrm{dtk} \\
& \text { Qjp }=\text { Qt } \times 1.75 \\
& =3.07 \times 1.75 \\
& =5.37 \mathrm{l} / \mathrm{dtk}
\end{aligned}
$$

\section{Perencanaan Broncaptering dan Reservoir \\ Desain bangunan penangkap mata air} (Broncaptering). Broncaptering yaitu bangunan yang di gunakan untuk menampung atau menangkap air yang keluar dari mata air. Titik-titik mata air di bungkus, kemudian dari dari bangunan air yang di bentuk ini, air dialirkan ke angunan reservoir yang ada.

Direncanakan dimensi broncaptering :

- Panjang= 2 meter

- Lebar $=1.5$ meter

- Tinggi $=1.5$ meter

Jadi volume broncaptering $=2 \times 1.5 \times 1.5$

$$
=4.5 \mathrm{~m}^{3} \text {. }
$$

Desain hidrolis Reservoir. Reservoir direncanakan pada daerah ketinggian yang merupakan elevasi tertinggi dari lokasi ke desa agar bisa di alirkan secara gravitasi dan direncanakan dekat dengan daerah layanan agar mudah di kontrol. Perhitungan reservoir sebagai berikut :

a. Volume kebutuhan di reservoir

- Kebutuhan rata-rata pada tahun $2035=$ $3.07 \mathrm{l} / \mathrm{dtk}$

- Kapasitas berguna reservoir di ambil sebesar $20 \%$ dari total kebutuhan air harian maksimum.

- Kpasitas berguna reservoir

$$
=0.20 \times 0.00307 \mathrm{~m}^{3} / \mathrm{dtk} \times(24 \times 3600)
$$$$
=53.02 \mathrm{~m}^{3} \text {. }
$$

Ukuran kapasitas berguna reservoir di tetapkan sebagai berikut :

Panjang $=5$ meter

Lebar $=4$ meter 
Tinggi $=2.7$ meter

Volume reservoir $=(5 \times 4 \times 2.7) \mathrm{m}$

$$
=54 \mathrm{~m}^{3}>\text { Kapasitas }
$$

Reservoir yang dibutuhkan :

$$
=54 \mathrm{~m}^{3}>53.02 \mathrm{~m}^{3}
$$

\section{Desain Jaringan Perpipaan Transmisi dan}

\section{Distribusi.}

\section{a. Perhitungan Pipa Transmisi}

Pipa transmisi merupakan pipa yang mengalirkan air dari broncaptering ke reservoir dan dimensi pipa transmisi akan lebih besar dari pipa distribusi.

Untuk analisis perhitungan sistem jaringan pipa transmisi adalah sebagai berikut.

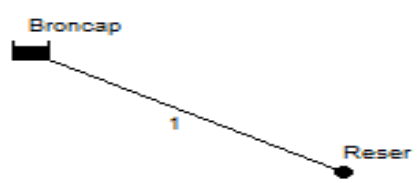

Gambar 2. Skema jaringa pipa Transmisi Perhitungan kecepatan pengaliran dalam pipa (v) dan headloss (Hf) pada pipa transmisi.

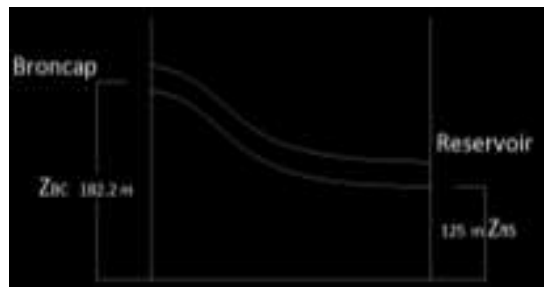

Gambar 3 . Pipa Transmisi

Data Perhitungan :

$\mathrm{ZA}=182.2 \mathrm{~m}$

$Z B=125 \mathrm{~m}$

$\mathrm{L}=3320 \mathrm{~m} \quad=3.320 \mathrm{Km}$

$\mathrm{D}=89 \mathrm{~mm} \quad=0.089 \mathrm{~m}$

$\mathrm{Q}=3.07 \mathrm{l} / \mathrm{dtk}=0.00307 \mathrm{~m}^{3} / \mathrm{dtk}$

Chw $=150$

a. Hitung Luas (A)

$$
A=\frac{\pi D^{2}}{4}=0.00622
$$

b. Hitung Headloss (Hf)

Perhitungan besarnya headloss dilakukan dengan menggukan persamaan 2.12

$\mathrm{Hf}=\frac{10.67 \times \mathrm{Q}^{1.852}}{\mathrm{C}_{\mathrm{HW}}{ }^{1.852} \times \mathrm{D}^{4.87}} \mathrm{~L}$

$\mathrm{Hf}=\frac{10.67 \times 0.00307^{1.852}}{150^{1.852} \times 0.089^{4.87}} 3320=9.588 \mathrm{~m}$

Headloss (Hf) per $\mathrm{km}=\frac{9.588}{3.320}=2.888 \mathrm{~m} / \mathrm{km}$

c. Hitung Kecepatan Aliran
Perhitungan kecepatan pengaliran dalam pipa dapat di hitung dengan rumus 2.2.

$$
\begin{aligned}
\mathrm{V} & =\mathrm{Q} / \mathrm{A} \\
& =0.00304 / 0.00622 \\
& =0.494 \mathrm{~m} / \mathrm{s}
\end{aligned}
$$

d. Hitung Tekanan Di Ujung Pipa

Tekanan di ujung pipa atau tiap titik sambung dapat di hitung berdasarkan tinggi tekanan pada tiap titik sambung. Besar tekanan dapat dihitung dengan persamaan 2.13.

$z_{R S}+\frac{P_{B C}}{\gamma}+\frac{v_{B C}{ }^{2}}{2 g}=z_{1}+\frac{P_{R S}}{\gamma}+\frac{v_{R S}{ }^{2}}{2 g}+h f$

$\frac{P_{R S}}{\gamma}=\mathrm{z}_{\mathrm{BC}}-\mathrm{z}_{\mathrm{RS}}-\mathrm{Hf}$

$\frac{P_{R S}}{\gamma}=182.2-125-9.588$

$\frac{P_{R S}}{\gamma}=47.612 \mathrm{~m}$

$\mathrm{P}_{\mathrm{RS}}=47.612 \times 1000 \times 9.81$

$P_{R S}=420,363.1 \mathrm{~Pa}$

\section{b. Perhitungan Pipa Distribusi}

Pipa distribusi merupakan pipa yang menyalurkan air dari reservoir ke konsumen dapat berupa SR, HU atau KU. Dalam perhitungan skripsi ini pemilihan dimensi pipa dilakukan dengan metode trial and error. Berikut merupakan analisa perhitungan pipa pada jaringan distribusi berdasarkan pembagian dusun.

\section{1). Perhitungan Pipa Distribusi dusun Batu} Tering A

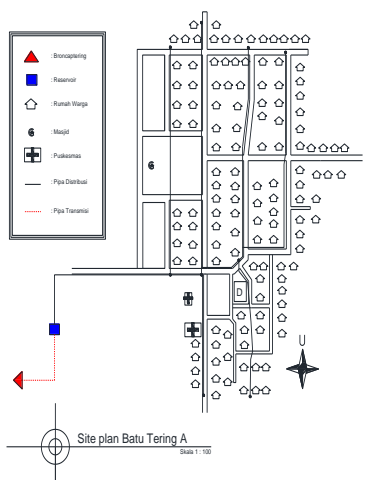

Gambar 4. Site plane Jaringan Dsn Batu Tering A

Dari gambar site plane jaringan dusun Batu Tering A dapat di gambarkan skema jaringan seperti di bawah ini. 


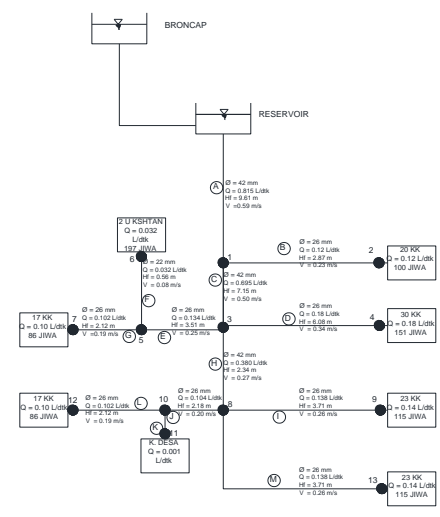

Gambar 5 . Skema Jaringan SR Dsn BatuTering $A$

Dari gambar skema jaringan pada halaman sebelumya dapat dihitung kecepatan pengaliran dalam pipa (v), headloss (Hf), dan besar tekanan pada pipa distribusi. Sebagai contoh perhitungan yaitu pipa A dari RS ke Node 1 adalah sebagai berikut : Data Perhitungan :

$$
\begin{aligned}
& Z_{R S}=125 \mathrm{~m} \\
& Z_{1}=113 \mathrm{~m} \\
& L=330 \mathrm{~m} \quad=0.330 \mathrm{Km} \\
& D=42 \mathrm{~mm} \quad=0.042 \mathrm{~m} \\
& Q=0.815 \mathrm{l} / \mathrm{dtk}=0.000815 \mathrm{~m}^{3} / \mathrm{dtk} \\
& C h w=150
\end{aligned}
$$

Hitung Luas (A)

$$
A=\frac{\pi D^{2}}{4}=0.00183
$$

Hitung Headloss (Hf)

\section{a. Headloss Mayor}

Perhitungan besarnya headloss Mayor dapat dilakukan dengan menggukan rumus 2.12 .

$$
\begin{aligned}
H f & =\frac{10.67 \times Q^{1.852}}{C_{H W}{ }^{1.852} \times D^{4.87}} L \\
H f & =\frac{10.67 \times 0.000815^{1.852}}{150^{1.852} \times 0.042^{4.87}} 330 \\
& =3.170 \mathrm{~m} \\
\mathrm{P}_{1} & =8.83 \times \gamma=0.833 \mathrm{~kg} / \mathrm{m}^{2} \\
\mathrm{P}_{1} & =8.830 \times 1000 \times 9.81 \\
\mathrm{P}_{1} & =77,961.0 \mathrm{~Pa}
\end{aligned}
$$

Dari hasil perhitungan di atas dapat simpulkan bahwa air dapat mengalir dari titik RS ke Node 1 karena adanya tekanan sebesar 77,961.0 $\mathrm{Pa}$, dan tekanan pada Node $1<\mathrm{P}$ (standar tekanan pipa PVC type
AW yaitu 980,670 $\mathrm{Pa}$, atau $10 \mathrm{kgf} / \mathrm{m}^{2}$ ) sehingga pipa di kategorikan aman.

Untuk perhitungan pipa lainnya dapat dilihat pada tabel 10 pada halaman berikutnya. 
Tabel 10. Rekapitulasi Hasil Perhitungan Jaringan Perpipaan Distribusi Dsn Batu Tering A

\begin{tabular}{|c|c|c|c|c|c|c|c|c|c|c|c|c|}
\hline & \multicolumn{10}{|c|}{ Batu Tering A } \\
\hline Node & Pipa & $\begin{array}{c}\text { Qd } \\
(\mathrm{I} / \mathrm{dtk})\end{array}$ & $\begin{array}{c}\mathrm{Q} \\
(\mathrm{I} / \mathrm{dtk})\end{array}$ & $\begin{array}{c}\mathrm{Ev} \\
(\mathrm{m})\end{array}$ & $\begin{array}{c}\mathrm{D} \\
(\mathrm{mm})\end{array}$ & $\begin{array}{c}\mathrm{L} \\
(\mathrm{m})\end{array}$ & $\mathrm{A}\left(\mathrm{m}^{2}\right)$ & $\begin{array}{c}\mathrm{Hf} \\
(\mathrm{m} / \mathrm{km})\end{array}$ & $\begin{array}{c}\mathrm{V} \\
(\mathrm{m} / \mathrm{s})\end{array}$ & $\frac{P}{\gamma}(\mathrm{m})$ & $\mathrm{P}(\mathrm{Pa})$ & $\begin{array}{c}\mathrm{P} \\
\left(\mathrm{kg} / \mathrm{m}^{2}\right)\end{array}$ \\
\hline 1 & $\mathrm{~A}$ & 0.000 & 0.815 & 113 & 42 & 330 & 0.0013847 & 9.61 & 0.59 & 8.83 & $86,623.32$ & 0.883 \\
\hline 2 & $\mathrm{~B}$ & 0.120 & 0.120 & 112 & 26 & 210 & 0.0005307 & 2.87 & 0.23 & 9.23 & $90,525.65$ & 0.923 \\
\hline 3 & $\mathrm{C}$ & 0.000 & 0.695 & 112 & 42 & 40 & 0.0013847 & 7.15 & 0.50 & 9.54 & $93,628.59$ & 0.954 \\
\hline 4 & $\mathrm{D}$ & 0.180 & 0.180 & 111 & 26 & 210 & 0.0005307 & 6.08 & 0.34 & 9.27 & $90,920.54$ & 0.927 \\
\hline 5 & $\mathrm{E}$ & 0.000 & 0.134 & 112 & 26 & 50 & 0.0005307 & 3.51 & 0.25 & 9.37 & $91,906.06$ & 0.937 \\
\hline 6 & $\mathrm{~F}$ & 0.032 & 0.032 & 112.2 & 22 & 20 & 0.0003799 & 0.56 & 0.08 & 9.16 & $89,835.10$ & 0.916 \\
\hline 7 & $\mathrm{G}$ & 0.102 & 0.102 & 109 & 26 & 110 & 0.0005307 & 2.12 & 0.19 & 12.14 & $119,045.86$ & 1.214 \\
\hline 8 & $\mathrm{H}$ & 0.000 & 0.380 & 112 & 42 & 50 & 0.0013847 & 2.34 & 0.27 & 9.43 & $92,480.13$ & 0.943 \\
\hline 9 & $\mathrm{I}$ & 0.138 & 0.138 & 110 & 26 & 200 & 0.0005307 & 3.71 & 0.26 & 10.68 & $104,811.61$ & 1.068 \\
\hline 10 & $\mathrm{~J}$ & 0.000 & 0.104 & 112 & 26 & 15 & 0.0005307 & 2.18 & 0.20 & 9.39 & $92,158.73$ & 0.939 \\
\hline 11 & $\mathrm{~K}$ & 0.00 & 0.002 & 111.8 & 22 & 20 & 0.0003799 & 0.00 & 0.00 & 9.59 & $94,120.31$ & 0.959 \\
\hline 12 & $\mathrm{~L}$ & 0.102 & 0.102 & 110 & 26 & 115 & 0.0005307 & 2.12 & 0.19 & 11.15 & $109,384.43$ & 1.115 \\
\hline 13 & $\mathrm{M}$ & 0.138 & 0.138 & 109 & 26 & 240 & 0.0005307 & 3.71 & 0.26 & 11.70 & $114,804.09$ & 1.170 \\
\hline
\end{tabular}

\section{Perhitungan Pipa Distribusi Dusun Batu}

Tering B

Berikut Merukpakan Site Plan Distribusi Dusun Batu Tering B :

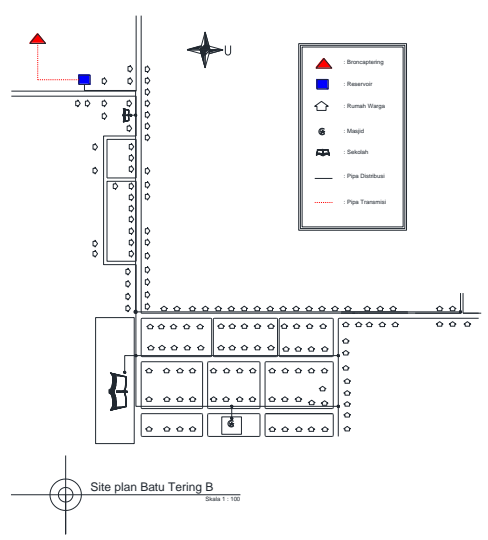

Gambar 6. Site Plan Jaringan Dusun Batu Tering B

Dari site plane dusun Batu Tering B pada halaman sebelumnya dapat di gambarkan skema jaringan seperti di bawah ini ;

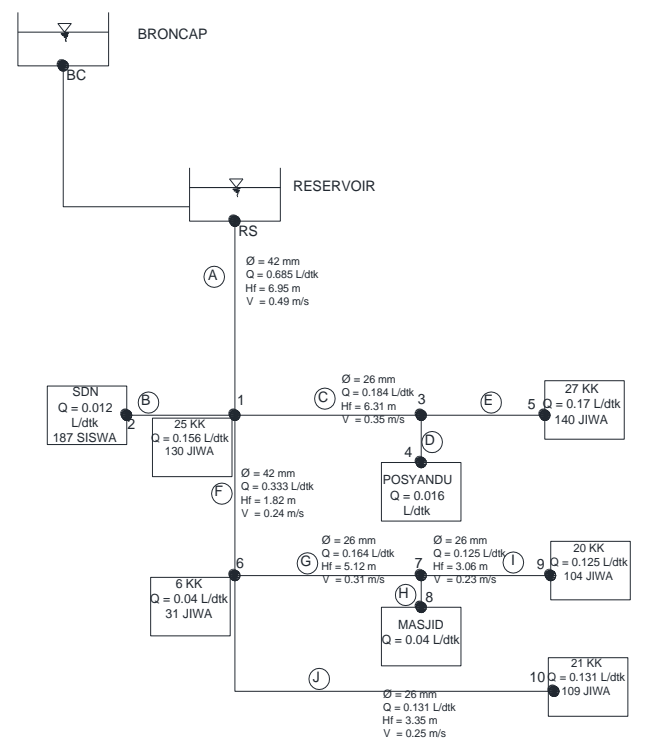

Gambar 7 . Skema Jaringan SR Dsn Batu Tering A

Dari skema di atas dapat dihitung besar aliran dalam pipa (v), headloss (hf) dan besar tekanan di ujung pipa, cara perhitungannya sama dengan cara perhitungan pada jaringan Dusun Batu Tering A. Untuk hasil perhitungan dapat dilihat pada tabel 11 dibawah ini : 
Tabel 11 . Rekapitulasi Hasil Perhitungan Jaringan Perpipaan Distribusi Dusun Batu Tering B

\begin{tabular}{|c|c|c|c|c|c|c|c|c|c|c|c|c|}
\hline \multicolumn{13}{|c|}{ Dusun Batu Tering B } \\
\hline Node & Pipa & $\underset{(\mathrm{l} / \mathrm{dtk})}{\mathrm{Qd}}$ & $\underset{(\mathrm{l} / \mathrm{dtk})}{\mathrm{Q}}$ & $\begin{array}{l}\text { Ev } \\
(\mathrm{m})\end{array}$ & $\begin{array}{c}D \\
(\mathrm{~mm})\end{array}$ & $\begin{array}{c}\mathrm{L} \\
(\mathrm{m})\end{array}$ & $A\left(m^{2}\right)$ & $\begin{array}{c}\mathrm{Hf} \\
(\mathrm{m} / \mathrm{km})\end{array}$ & $\begin{array}{c}V \\
(\mathrm{~m} / \mathrm{s})\end{array}$ & $\begin{array}{c}\frac{P}{\gamma} \\
(\mathrm{m})\end{array}$ & $P(P a)$ & $\begin{array}{c}\mathrm{P} \\
\left(\mathrm{kg} / \mathrm{m}^{2}\right)\end{array}$ \\
\hline 1 & A & 0.000 & 0.869 & 122 & 42 & 80 & 0.0013847 & 10.81 & 0.63 & 2.14 & $20,947.02$ & 0.214 \\
\hline 2 & B & 0.002 & 0.002 & 122 & 22 & 50 & 0.0003799 & 0.00 & 0.01 & 2.14 & $20,945.42$ & 0.214 \\
\hline 3 & C & 0.252 & 0.867 & 115 & 42 & 210 & 0.0013847 & 10.76 & 0.63 & 6.87 & $67,441.94$ & 0.687 \\
\hline 4 & D & 0.236 & 0.236 & 111 & 26 & 285 & 0.0005307 & 9.96 & 0.44 & 8.04 & $78,847.93$ & 0.804 \\
\hline 5 & $E$ & 0.000 & 0.379 & 114 & 42 & 60 & 0.0013847 & 2.33 & 0.27 & 7.74 & $75,882.80$ & 0.774 \\
\hline 6 & $\mathrm{~F}$ & 0.179 & 0.179 & 113 & 26 & 210 & 0.0005307 & 6.02 & 0.34 & 7.47 & $73,298.26$ & 0.747 \\
\hline 7 & G & 0.014 & 0.014 & 114 & 22 & 50 & 0.0003799 & 0.12 & 0.04 & 7.73 & $75,824.23$ & 0.773 \\
\hline 8 & $\mathrm{H}$ & 0.000 & 0.186 & 113 & 26 & 130 & 0.0005307 & 6.41 & 0.35 & 7.90 & $77,514.66$ & 0.790 \\
\hline 9 & 1 & 0.040 & 0.040 & 113 & 22 & 30 & 0.0003799 & 0.84 & 0.11 & 7.88 & $77,267.57$ & 0.788 \\
\hline 10 & $\mathrm{~J}$ & 0.146 & 0.146 & 112 & 26 & 50 & 0.0005307 & 4.10 & 0.27 & 8.67 & $85,068.60$ & 0.867 \\
\hline
\end{tabular}

\section{Perhitungan Pipa Distribusi Dusun}

Sela

Berikut merupakan gambar site plane jaringan distribusi dusun Sela :

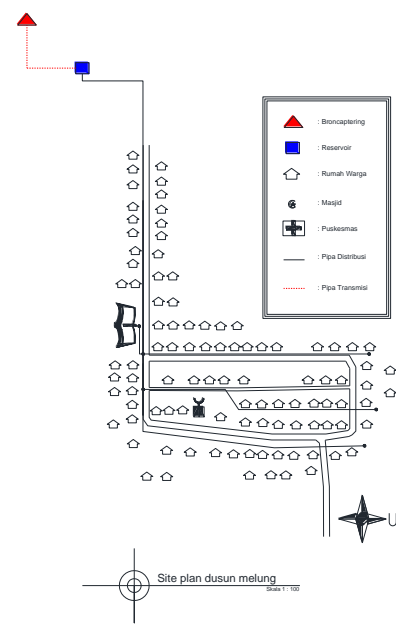

Gambar 8 . Sitplan JaringanSR Dsn Sela

Dari siteplane dusun Sela pada halaman sebelumnya dapat di gambarkan skema jaringan seperti di bawah ini

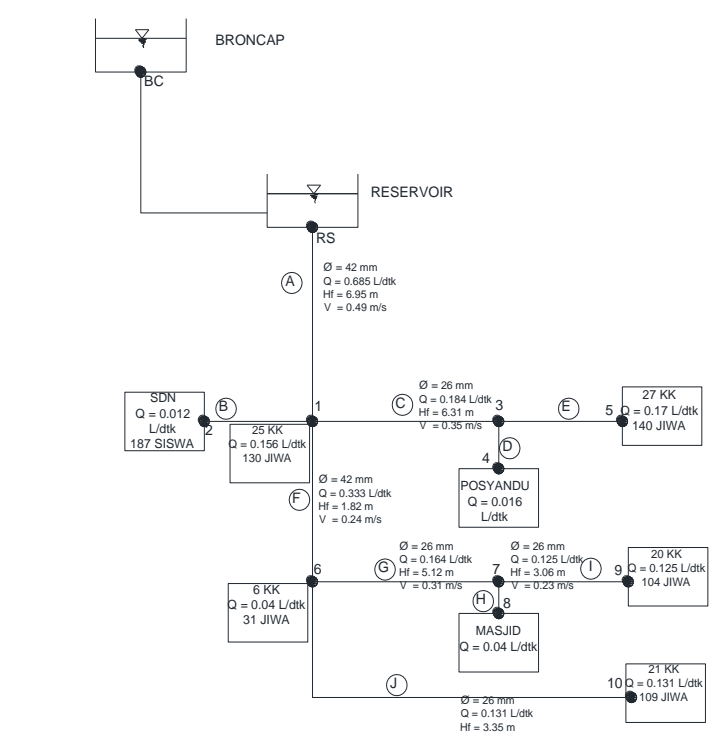

Gambar 9 . Skema Jaringan SR 'Dsn Sela

Dari skema di atas dapat dihitung besar aliran dalam pipa (v), headloss (hf) dan besar tekanan di ujung pipa, cara perhitungannya sama dengan cara perhitungan pada jaringan Dusun Batu Tering A. Untuk hasil perhitungan dapat dilihat pada tabel 12 pada halaman berikutnya. 
Tabel 12 . Rekapitulasi Hasil Perhitungan Jaringan Perpipaan Distribusi Dusn Sela

\begin{tabular}{|c|c|c|c|c|c|c|c|c|c|c|c|c|}
\hline \multicolumn{10}{|c|}{ Dusun Sela } \\
\hline Node & Pipa & $\begin{array}{c}\text { Qd } \\
(\mathrm{l} / \mathrm{dtk})\end{array}$ & $\begin{array}{c}\mathrm{Q} \\
(\mathrm{l} / \mathrm{dtk})\end{array}$ & $\begin{array}{c}\mathrm{Ev} \\
(\mathrm{m})\end{array}$ & $\begin{array}{c}\mathrm{D} \\
(\mathrm{mm})\end{array}$ & $\begin{array}{c}\mathrm{L} \\
(\mathrm{m})\end{array}$ & $\mathrm{A}\left(\mathrm{m}^{2}\right)$ & $\begin{array}{c}\mathrm{Hf} \\
(\mathrm{m} / \mathrm{km})\end{array}$ & $\begin{array}{c}\mathrm{V} \\
(\mathrm{m} / \mathrm{s})\end{array}$ & $\frac{P}{\gamma}(\mathrm{m})$ & $\mathrm{P}(\mathrm{Pa})$ & $\mathrm{P}\left(\mathrm{kg} / \mathrm{m}^{2}\right)$ \\
\hline 1 & A & 0.156 & 0.685 & 102 & 42 & 965 & 0.0013847 & 6.95 & 0.49 & 16.29 & $159,820.9$ & 1.629 \\
\hline 2 & B & 0.012 & 0.012 & 102 & 22 & 50 & 0.0003799 & 0.10 & 0.03 & 16.29 & $159,773.6$ & 1.629 \\
\hline 3 & $\mathrm{C}$ & 0.000 & 0.184 & 101.4 & 26 & 110 & 0.0005307 & 6.31 & 0.35 & 16.20 & $158,901.1$ & 1.620 \\
\hline 4 & $\mathrm{D}$ & 0.016 & 0.016 & 101.4 & 26 & 80 & 0.0005307 & 0.07 & 0.03 & 16.19 & $158,847.6$ & 1.619 \\
\hline 5 & $\mathrm{E}$ & 0.168 & 0.168 & 101 & 22 & 50 & 0.0003799 & 12.03 & 0.44 & 16.00 & $156,926.3$ & 1.600 \\
\hline 6 & $\mathrm{~F}$ & 0.037 & 0.333 & 101.6 & 42 & 45 & 0.0013847 & 1.82 & 0.24 & 16.61 & $162,939.3$ & 1.661 \\
\hline 7 & $\mathrm{G}$ & 0.000 & 0.164 & 101.5 & 26 & 60 & 0.0005307 & 5.12 & 0.31 & 16.40 & $160,907.5$ & 1.640 \\
\hline 8 & $\mathrm{H}$ & 0.040 & 0.040 & 101.5 & 22 & 50 & 0.0003799 & 0.84 & 0.11 & 16.36 & $160,495.6$ & 1.636 \\
\hline 9 & $\mathrm{I}$ & 0.125 & 0.125 & 101 & 26 & 130 & 0.0005307 & 3.06 & 0.23 & 16.50 & $161,912.7$ & 1.650 \\
\hline 10 & $\mathrm{~J}$ & 0.131 & 0.131 & 100 & 26 & 245 & 0.0005307 & 3.35 & 0.25 & 17.39 & $170,590.7$ & 1.739 \\
\hline
\end{tabular}

Perhitungan Pipa Distribusi dusun Melung

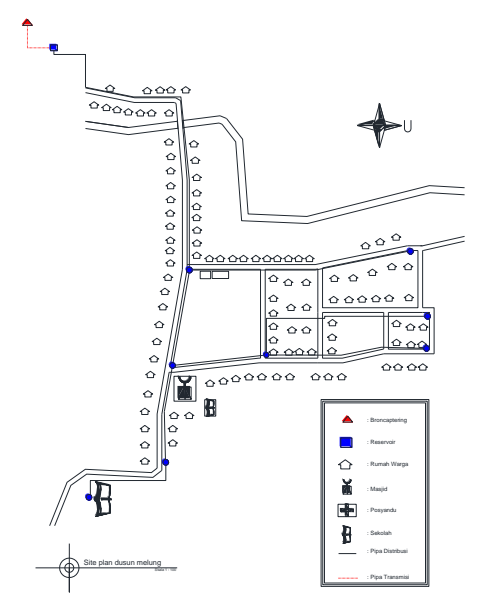

Gambar 10. Site plan Jaringan SR Dusun Melung

Dari siteplane dusun Melung pada halaman sebelumnya dapat di gambarkan skema jaringan seperti di bawah ini

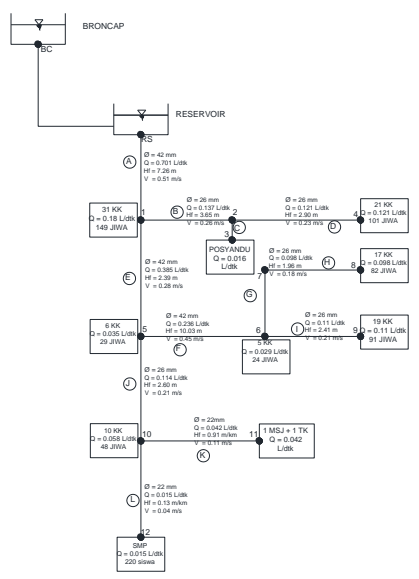

Dari skema di atas dapat dihitung kecepatan aliran dalam pipa (v), headloss (hf) dan besar tekanan di ujung pipa, cara perhitungannya sama dengan cara perhitungan pada jaringan Dusun Batu Tering A. Untuk hasil perhitungan dapat dilihat pada tabel 13 pada halaman berikutnya. 
Tabel 13. Rekapitulasi Hasil Perhitungan Jaringan Perpipaan Distribusi Dusun Melung

\begin{tabular}{|c|c|c|c|c|c|c|c|c|c|c|c|c|}
\hline \multicolumn{13}{|c|}{ Dusun Melung } \\
\hline Node & Pipa & $\underset{(\mathrm{l} / \mathrm{dtk})}{\mathrm{Qd}}$ & $\underset{(\mathrm{l} / \mathrm{dtk})}{\mathrm{Q}}$ & $\begin{array}{l}\text { Ev } \\
(\mathrm{m})\end{array}$ & $\begin{array}{c}\mathrm{D} \\
(\mathrm{mm})\end{array}$ & $\begin{array}{c}\mathrm{L} \\
(\mathrm{m})\end{array}$ & $A\left(m^{2}\right)$ & $\begin{array}{c}\mathrm{Hf} \\
(\mathrm{m} / \mathrm{km})\end{array}$ & $\begin{array}{c}\mathrm{V} \\
(\mathrm{m} / \mathrm{s})\end{array}$ & $\begin{array}{c}\frac{P}{\gamma} \\
(\mathrm{m})\end{array}$ & $\mathrm{P}(\mathrm{Pa})$ & $\begin{array}{c}\mathrm{P} \\
\left(\mathrm{kg} / \mathrm{m}^{2}\right)\end{array}$ \\
\hline 1 & $A$ & 0.179 & 0.701 & 99 & 42 & 1540 & 0.0013847 & 7.26 & 0.51 & 14.82 & $145,376.1$ & 1.482 \\
\hline 2 & $B$ & 0.000 & 0.137 & 99 & 26 & 35 & 0.0005307 & 3.65 & 0.26 & 14.69 & $144,121.8$ & 1.469 \\
\hline 3 & $\mathrm{C}$ & 0.016 & 0.016 & 99.2 & 22 & 50 & 0.0003799 & 0.15 & 0.04 & 14.48 & $142,084.3$ & 1.448 \\
\hline 4 & $D$ & 0.121 & 0.121 & 94 & 26 & 185 & 0.0005307 & 2.90 & 0.23 & 19.15 & $187,901.1$ & 1.915 \\
\hline 5 & $E$ & 0.035 & 0.385 & 104 & 42 & 90 & 0.0013847 & 2.39 & 0.28 & 9.60 & $94,211.9$ & 0.960 \\
\hline 6 & $\mathrm{~F}$ & 0.029 & 0.236 & 102 & 26 & 85 & 0.0005307 & 10.03 & 0.45 & 10.75 & $105,471.3$ & 1.075 \\
\hline 7 & G & 0.000 & 0.098 & 101 & 26 & 45 & 0.0005307 & 1.96 & 0.18 & 11.66 & $114,414.4$ & 1.166 \\
\hline 8 & $\mathrm{H}$ & 0.098 & 0.098 & 95 & 26 & 100 & 0.0005307 & 1.96 & 0.18 & 17.47 & $171,348.1$ & 1.747 \\
\hline 9 & 1 & 0.110 & 0.110 & 95 & 26 & 105 & 0.0005307 & 2.41 & 0.21 & 17.50 & $171,656.0$ & 1.750 \\
\hline 10 & $\mathrm{~J}$ & 0.058 & 0.114 & 105 & 26 & 80 & 0.0005307 & 2.60 & 0.21 & 8.40 & $82,361.3$ & 0.840 \\
\hline 11 & K & 0.042 & 0.042 & 105 & 22 & 40 & 0.0003799 & 0.91 & 0.11 & 8.36 & $82,003.3$ & 0.836 \\
\hline 12 & $\mathrm{~L}$ & 0.015 & 0.015 & 108 & 22 & 320 & 0.0003799 & 0.13 & 0.04 & 5.35 & $52,519.9$ & 0.535 \\
\hline
\end{tabular}

\section{Pemilihan Jenis Pipa}

Pipa yang digunakan dalam perencanaan ini adalah pipa PVC.Karena pipa PVC dalam plumbing merupakian inovasi dan terobosan yang hebat baik segi kualitas ataupun segi biaya. Adapun keunggulan yang dimiliki antara lain :

Kelenturan yang tinggi (kekuatan tarik $\geq$

22 Mpa dan kelenturan $\geq 400 \%$ )

a. Memiliki kemampuan untuk menahan beban kejut ( impact strength ) yang tinggi.

b. Tahan terhadap temperature rendah.

c. Ringan, dengan masa jenis (density) $\geq$ $0,94 \mathrm{~kg} / \mathrm{m} 3$ sehingga mudah untuk handing dan transportasi.

d. Mudah dan cepat pada penyambungan dan pemanasan.

e. Tahan karat dan tahan abrasive

f. Permukaan halus sengga pengaruh kehilangan tekanan sanggat kecil.

g. Tidak mengandung zat - zat beracun sehingga direkomendasikan sangat aman untuk system distribusi air minum.

h. Usia pipa ( life time ) dapat mencapai 50 tahun.

Satu satunyan kelemahan pipa PVC adalah rawan bocor apabila system pengeleman kurang rapi. Meski demikian pipa PVC merupakan alternative yang paling banyak dipakai masyarakat luas saat ini.

\section{KESIMPULAN}

1. Kebutuhan Air Bersih desa Batu Tering 20 tahun kedepan adalah sebesar $3.07 \mathrm{l} / \mathrm{dtk}$, berikut pembagian kebutuhan air bersih untuk masing - masing dusun :

a. Kebutuhan Air bersih dusun Batu Tering A sebesar 0.814 l/dtk.

b. Kebutuhan Air bersih dusun BAtu Tering B sebesar 0.869 l/dtk/

C. Kebutuhan air bersih dusun Sela Sebesar 0.684 l/dtk

d. Kebutuhan air bersih dusun Melung sebesar $0.701 \mathrm{l} / \mathrm{dtk}$.

2. Sistem jaringan air bersih yang efisien untuk akses air bersih yang dapat di terapkan di desa Batu tering adalah dengan menggunakan jaringan sambungan rumah (SR), dan pipa transmisi yang digunakan adalah pipa PVC dengan diameter 3", dan pipa distribusi dengan diameter $1 \frac{1 / 4}{}$ ", dan $3 / 4 "$.

\section{SARAN}

1. Perlu di buat suatu system operasional dan pemeliharaan system penyediaan air bersih di desa batu tering

2. Pentingnya untuk menjaga daerah sekitar mata air, mengingat mulai banyaknya pembukaan lahan baru. 


\section{DAFTAR PUSTAKA}

Anonim. 2016. Kecamatan Moyo Hulu dalam Angka. Sumbawa: BPS Kabupaten Sumbawa.

Anonim. 2012. Petunjuk Praktis Perencanaan Pembangunan Sistem Penyediaan Air Bersih Perdesaan. Jakarta: Departemen Pekerjaan Umum Direktorat Jendral Cipta Karya.

Binilang, Alex. dkk. 2015. Perencanaan Sistem Penyediaan Air Bersih di Desa Taratara Kecamatan Tomohon Barat. Manado: Universitas Sam Ratulangi.

Hau'Oni, kris. and Nugroho, Doda G. 2011. Pengoperasian \& prasarana air bersih Sistem Gravitasi. Jakarta: Deutsche Gesellschaft fürInternationale Zusammenarbeit (GIZ) GmbH.

K, Linsey, Ray. 1996. Teknik Sumber Daya Air.Bandung: Erlangga.

Krisnayanti. dkk. 2013. Studi Perencanaan Pengembangan Penyediaan Air Bersih Di Kecamatan Kupang Timur Kabupaten Kupang. Kupang : Universitas Nusa Cendana.

Makrup, Lalu. 2001. Dasar-dasar Analisis Aliran di Sungai dan Muara. Yogyakarta : UII Press Yogyakarta. 